\title{
DEIXA QUE DIGAM, PENSEM, FALEM: REPRESENTAÇÕES JUVENIS SOBRE A VIOLÊNCIA RACIAL NO TERRITÓRIO ESCOLAR
}

\author{
Ângela Maria Pereira da Silva ${ }^{1}$ \\ Bianca Salazar Guizzo ${ }^{2}$
}

\section{Os aspectos metodológicos}

Abordar-se-á o percurso metodológico trilhado para constituição do material empírico utilizado para discussão neste artigo. Foram realizadas entrevistas narrativas com oito jovens estudantes vinculados/as a uma escola da rede pública do território Guajuviras em Canoas/RS. O roteiro semiestruturado contemplou perguntas preestabelecidas, e surgiram outras perguntas ao longo da produção dos dados. Para Silva (1995: 204), as narrativas constituem-se uma prática discursiva relevante, pois "[...] contam histórias sobre nós e o mundo que nos ajudam a dar sentido, ordem às coisas do mundo e a estabilizar e fixar ao menos provisoriamente nosso eu".

O estudo respeitou os aspectos éticos da pesquisa com seres humanos, conforme estabelecido pela Resolução $n^{\circ} 466$ do ano de 2012, do Ministério da Saúde. A realização das entrevistas ocorreu após os/as participantes lerem e assinarem o Termo de Consentimento Livre e Esclarecido, em duas vias, sendo que uma via ficou em posse das pesquisadoras e a outra com a/o participante.

Para resguardar a identidade dos/as jovens entrevistados/as, foi sugerido que escolhessem nomes de plantas ornamentais, de livre escolha. Então, logo no início da entrevista narrativa, cada um/a fez a sua opção. No quadro a seguir, descrevemos brevemente cada um/a dos/as participantes:

\section{Quadro 1}

\begin{tabular}{|c|l|}
\hline Participante & \multicolumn{1}{|c|}{ Descrição } \\
\hline JASMIM & Tem 19 anos, é solteira, cursa o $3^{\circ}$ ano, nasceu no \\
bairro e estuda há dois anos na escola da rede \\
estadual do Guajuviras, por conta de trabalho, de \\
curso militar na época e em função dos seus
\end{tabular}

\footnotetext{
${ }^{1}$ Universidade Luterana do Brasil/Campus Canoas, Brasil. E-mail: angelmsilva@gmail.com. ORCID: https://orcid.org/0000-0001-8793-4620

${ }^{2}$ Universidade Luterana do Brasil/Campus Canoas, Brasil. E-mail: bguizzo_1@ @hotmail.com. ORCID: https://orcid.org/0000-0003-1080-2210
} 


\begin{tabular}{|c|c|}
\hline & horários. \\
\hline ROSA AZUL & $\begin{array}{l}\text { Tem } 22 \text { anos, é solteira, cursa o } 3^{\circ} \text { ano, tem um } \\
\text { filho de quatro anos, reside com sua família e } \\
\text { estuda há três anos na escola da rede estadual desse } \\
\text { território. }\end{array}$ \\
\hline FLOR DE GIRASSOL & $\begin{array}{l}\text { Tem } 18 \text { anos, é casada, está no } 3^{\circ} \text { ano e estuda há } \\
\text { escola da rede estadual, desde o } 1^{\circ} \text { ano do Ensino Mé }\end{array}$ \\
\hline TULIPA & $\begin{array}{l}\text { Tem } 18 \text { anos de idade, em união estável com o pai } \\
\text { do seu filho, de um ano e nove meses, está } \\
\text { cursando o } 3^{\circ} \text { ano do Ensino Médio e mudou-se de } \\
\text { Nova Santa Rita para o bairro Guajuviras há cerca } \\
\text { de um ano, pelo acesso à moradia e procura de } \\
\text { emprego. }\end{array}$ \\
\hline DAMA DA NOITE & $\begin{array}{l}\text { Jovem escolar com } 20 \text { anos, solteiro, } 3^{\circ} \text { ano, mora } \\
\text { no Guajuviras desde que nasceu. }\end{array}$ \\
\hline ARUEIRA & $\begin{array}{l}\text { Jovem escolar com } 18 \text { anos, solteiro, reside desde } \\
\text { os três anos de idade no bairro. }\end{array}$ \\
\hline ORQUÍDEA & $\begin{array}{l}\text { Tem } 18 \text { anos, é solteiro, cursa o } 3^{\circ} \text { ano e trabalha no } \\
\text { Centro de Canoas. }\end{array}$ \\
\hline GIRASSOL & $\begin{array}{l}\text { Com } 18 \text { anos, solteiro, cursa o } 3^{\circ} \text { ano; veio para a esc } \\
\text { estadual para assumir-se gay, pois temia a rejeição en } \\
\text { anteriores. }\end{array}$ \\
\hline
\end{tabular}

Fonte: Autoras (2021).

As entrevistas foram gravadas e transcritas do modo próximo do estilo dos/as participantes, e pequenos excertos foram feitos para auxiliar a compreensão do contexto. Ressalta-se que esse momento já se constituiu em uma pré-análise do material.

No que se refere à escola em que foi realizada a pesquisa, é importante mencionar que contempla os três turnos, assim proporciona aos moradores de diferentes faixas etárias a possibilidade de acesso ao direito à educação. A escola dispõe de um projeto político pedagógico condizente à realidade do território. A instituição escolar, na atualidade, deveria buscar aproximações com as produções culturais presentes na sociedade e também com as práticas vivenciadas pelos sujeitos, em que as práticas sociais podem ser (res)significadas continuamente (Vargas, 2008).

Dito isso, a escola, dispõe de uma equipe diretiva composta por diretora, vicediretores por turno, orientação educacional, supervisão escolar, um assistente financeiro, 15 profissionais e 56 professores, círculo de pais e mestres, conselho escolar e caixa 
escolar (PPP, 2018). A instituição é mantida pelo repasse de verbas do estado e do Governo Federal. Ela representa um importante espaço de sociabilidade no território, devido a sua atuação junto à comunidade.

\section{Ferramentas teórico-conceituais}

Os conceitos do campo dos Estudos Culturais sobre representações, identidades, juventudes, as suas intersecções com as questões étnico-raciais tornam-se úteis no âmbito deste artigo. Para Stuart Hall (1997), a identidade social dos indivíduos baseiase em três concepções: a concepção de identidade do iluminismo, que apregoava o indivíduo centrado, unificado, tendo a razão e a consciência como centro; o essencialismo, isto é, a crença de que o indivíduo nasce com uma essência invariável; e a do sujeito pós-moderno, que não tem uma identidade fixa, permanente, a qual pode ser transformada continuamente e está inter-relacionada com as formas pelas quais as/os jovens que frequentavam a escola pesquisada são representados/as ou interpelados/as nos sistemas culturais que os/as rodeiam.

Uma vez que as identidades se tornam cada vez menos fixas ou permanentes, conforme Hall (2005: 13), passam a ser "uma celebração móvel transformada continuamente e relacionadas às formas como somos interpelados ou representados nos sistemas culturais que nos rodeiam”. Em meio a esse processo mencionado por Hall (2005), há uma multiplicidade de identidades e essas são cambiantes, contraditórias e continuamente deslocadas. Costa (2010) ressalta que na contemporaneidade tem se produzido novos modos de viver, a partir de várias fontes de inspiração para as identidades.

Nessa direção, as multifacetadas identidades forjadas pela e na cultura, estão sendo cada vez mais deslocadas e fragmentadas nos diversos contextos socioculturais, tais como: nos campos da educação, do trabalho e da vida familiar. São novas linguagens que ecoam das periferias, por meio das quais as populações jovens imprimem as suas histórias de vida.

Debert (1998: 16) destaca que:

O fato de a idade cronológica não estar ligada a um aparato que domina a reflexão sobre os estágios de maturidade mostra também a flexibilidade desse mecanismo para a criação de novas etapas e a redefinição de direitos e obrigações. Essa fluidez, mas, ao mesmo tempo, efetividade na definição de experiências individuais e coletivas, transforma a idade cronológica em um 


\section{Cidades em metamorfose: memórias, percursos urbanos e imagens}

elemento simbólico extremamente econômico no estabelecimento de laços entre grupos bastante heterogêneos no que diz respeito a outras dimensões.

Desse modo, essa periodização não é natural, mas uma construção social e cultural, constituídas como problemáticas, à medida que envolve um projeto de civilidade; noção de infância, juventude e envelhecência quando se tornam uma problemática social (aplicar determinadas medidas legais, conceder ou não certos benefícios sociais), ou seja, abarca uma série de regulações nesse tempo da vida.

Conforme Hall (1997: 25), “a representação é uma prática, um tipo de trabalho, que usa os objetos materiais e efeitos". Sendo assim, no Brasil, os limites entre infância, juventude e envelhecimento são demarcados no âmbito legal por faixas etárias, tal como consta no Estatuto da Criança e do Adolescente, no Estatuto do Idoso e no Estatuto da Juventude. Esses documentos servem como um marcador em diversas políticas sociais para o acesso ou não a determinados direitos sociais. Os/as jovens são fecundos agentes sociais e o desafio consiste em considerá-los/as não a partir de delimitações biológicas ou como um contínuo temporal e ahistórico, mas como "sujeitos de discurso, com capacidade de apropriar-se e mobilizar os objetos tanto sociais e simbólicos como materiais" (Reguillo, 2000: 36).

Para Dayrell (2003: 24), uma das ideias "mais arraigadas é a juventude vista na sua condição de transitoriedade, onde o jovem é um "vir a ser", tendo no futuro, na passagem para a vida adulta, o sentido das suas ações no presente". Os estudos sobre a condição juvenil, ao longo do século XX, oscilavam na percepção dos jovens como motores de mudanças da sociedade e até como um grupo potencialmente perigoso ou ameaçador, em diferentes sentidos (Sposito, 2009). Assim, os atravessamentos sociais e culturais, produzem identidades e juventudes múltiplas, ou seja, nos fazem pensar sobre sujeitos em constante liquidez e transitoriedade.

Assim, temos identidades e juventudes plurais, cambiantes, constituídas em um mundo que se modifica constantemente, fluído e em transformação. O engajamento social e político dos jovens, sobretudo, numa conjuntura de contrarreformas das políticas sociais, com os avanços do conservadorismo, fundamentalismos religiosos que reforçam a cultura patriarcal, racista e heterossexista representam um desafio.

Deste modo, o território escolar configura-se como um dos espaços de circulação de identidades juvenis em que são observadas as condições sócio-históricoculturais. Para Dayrell (2002: 124), “os jovens pobres inserem-se, mesmo que de forma restrita e desigual, em circuitos de informações, por meio dos diferentes veículos da 
mídia, e sofrem o apelo da cultura de consumo, estimulando sonhos e fantasias”. Assim, também é observado na desigualdade de oportunidades educacionais, à medida que o Estado se desobriga das responsabilidades de ensino para a iniciativa privada.

Cabe pensar ainda que os espaços da vida dos jovens demandam perspectivas transversais. Na perspectiva de Sposito (2009), a dimensão transversal ainda carece de estudos sobre juventude com relação aos modos de vida de jovens a partir de seu local de moradia, considerado como um território de múltiplas relações sociais que envolvem escola, família, trabalho, lazer, sociabilidade. Ressalta-se que a escola parece não ser mais pensada como um elemento estruturante da aprendizagem, mas cada vez mais destinada para o trabalho educativo em suas dimensões sociais e assistenciais.

Dentre estas perspectivas transversais encontram potências as discussões sobre as questões de gênero e sexualidade em articulação com as violências. Sobre o conceito de gênero respaldamo-nos em estudiosas/os que o compreendem como uma categoria relacional, ou seja, a partir de uma lógica que abrange o feminino e o masculino, pois para entendermos a construção do feminino faz-se necessário considerarmos as relações culturais, sociais e históricas que estão interligadas à formação do masculino e viceversa. Felipe (2007) argumenta que é importante:

[...] ressaltar a produtividade do conceito de gênero como ferramenta teórica e política na reflexão a respeito das subalternidades, abalando certezas tão firmemente alicerçadas em torno das diferenças biológicas, que serviram durante muito tempo para justificar as desigualdades entre homens e mulheres (Felipe, 2007: 78).

Essa abordagem de gênero foi narrada pelos/as jovens entrevistados/as neste estudo, à medida que alguns/algumas referiram piadas desrespeitosas, insinuações e comentários depreciativos em relação às diversidades de gênero, orientação sexual, raça-etnia/cor, faixa etária, classe social, dentre outras.

Essa prática é evidenciada nos silenciamentos no território escolar, uma vez que, os/as participantes acabam por reproduzir certos discursos machistas, heterossexistas, homofóbicos que apagam as diversidades. Portanto, a constituição das juventudes é atravessada por contextos e vivências de violências de gênero no cotidiano escolar. Louro (2000) chama a atenção para o fato de que as mulheres e os homens precisam estar atentas/os às relações de poder que se inscrevem nas dinâmicas sociais, pois ambos/as tomam parte. Desse modo, desnaturalizar determinadas situações, comportamentos e práticas sociais permeadas pelas violências na/da escola nos desafia 
constantemente na condição de estudiosos/as, técnicos/as, professores/as. Diante disso, a necessidade de serem viabilizados espaços de reflexão e debate sobre os atravessamentos de classe, gênero, sexualidade, raça-etnia nos territórios escolares.

Há que se ressaltar a intolerância que acaba por interferir na diminuição da desigualdade de gênero e para ações efetivas de consolidação dos direitos humanos dos sujeitos implicados no território escolar (alunos/as, professores/as, corpo diretivo e famílias). Isso fica evidenciado na observação com relação aos banheiros femininos na escola, lócus da pesquisa, por meio de adjetivos pejorativos e palavras de baixo calão contidas nas portas que intimidam e desqualificam uns/umas aos/as outros/as e, inclusive, algumas proferidas com os nomes de estudantes, boa parte relacionadas às marcas no corpo.

A partir de tal perspectiva, entendemos que as/os jovens participantes dessa pesquisa, constituem-se através de "práticas sociais masculinizantes e feminilizantes, em consonância com as diversas concepções de cada sociedade" (Louro, 2011: 103). Dito isso, ainda persistem muitos resquícios de quais feminilidades e masculinidades são mais aceitas e quais são rejeitadas no território escolar. Para Meyer (2004), esse modo de teorizar gênero remete a todas as formas de construção social, cultural e linguística que diferenciam mulheres de homens, incluindo aqueles processos que produzem seus corpos, distinguindo-os e nomeando-os como corpos dotados de sexo, gênero e sexualidade.

Dal'Igna, Klein e Meyer (2016) discutem que não se trata apenas de seleção e organização dos conhecimentos contidos no currículo, mas também de analisar o que esses processos implicam em termos de inclusão e exclusão. No que consistem, tais formas de organização? Em que medida as escolas atribuem diferentes valores aos conhecimentos e aos sujeitos? Quais as relações entre políticas públicas, produção de conhecimentos, identidades dos sujeitos alunos/as, a partir dessas narrativas, representações e leituras? Neste sentido, as dimensões políticas e de poder acabam por definir o que é legítimo e ilegítimo, quem se aproxima e quem se distancia de uma suposta norma de gênero, de raça-etnia/cor, de sexualidade e de classe a ser incorporada e seguida.

Assim, faz-se necessário, evidenciar um pensamento que singulariza, conflitua e subverte relações políticas, de conhecimento e de poder, assim como formas de sujeição de e entre homens e mulheres, acolhendo e estimulando a emergência de novas formas de viver as feminilidades e as masculinidades além do biológico, no gênero e 
sexualidade (Dal'igna; Klein; Meyer, 2016). Diante disso, se tomarmos o espaço escolar, será pelo silenciamento, pela proibição sistemática de emergência do corpo sexuado de alunos/as, sem falar no corpo sexuado dos/as professores/as, que as coisas sobre o sexo se fazem presentes (Louro, 2011). Um corpo que se constitui como problema econômico, político, social, científico e médico-biológico (Gadelha, 2009: 112.

Para Meyer (2004) educar engloba um complexo de forças e de processos no interior dos quais indivíduos são transformados em homens e mulheres e ao mesmo tempo se reconhecem como sujeitos femininos e masculinos. Sexualidade é um artefato cultural e histórico, construído e sustentado por relações de poder, e que diferentes sujeitos têm diferentes modos de viver e compreender a sexualidade, assim torna-se matéria escolar (Carrara, 2010).

\section{Variações de tensão: a dor da cor}

As violências perpetradas contra jovens é um fenômeno disseminado no país e que tem crescido nas últimas décadas. Os/as jovens representam um quarto da população brasileira e estão entre as maiores vítimas de violência letal. A violência contra a juventude negra atingiu índices alarmantes no Brasil e representa uma das principais expressões das desigualdades raciais conforme os indicadores do Atlas da Violência 2020. Há que se ressaltar que os/as jovens negros/as figuram como as principais vítimas de homicídios e as taxas de mortes se sobressaem, em especial, nas pessoas negras do sexo masculino. Esses apresentam crescimento ao longo dos anos, se comparado aos índices de mortalidade de brancos que, em muitos casos, apresentam redução.

\footnotetext{
Apenas em 2018, para citar o exemplo mais recente, os negros (soma de pretos e pardos, segundo classificação do IBGE) representaram 75,7\% das vítimas de homicídios, com uma taxa de homicídios por 100 mil habitantes de 37,8. Comparativamente, entre os não negros (soma de brancos, amarelos e indígenas) a taxa foi de 13,9, o que significa que, para cada indivíduo não negro morto em 2018, 2,7 negros foram mortos. Da mesma forma, as mulheres negras representaram $68 \%$ do total das mulheres assassinadas no Brasil, com uma taxa de mortalidade por 100 mil habitantes de 5,2, quase o dobro quando comparada à das mulheres não negras (Cerqueira, 2020: 13).
}

Como problematiza Waiselfisz (2016), por meio da série Mapa da Violência, a taxa de homicídios por arma de fogo na população de 15 a 29 anos subiu 669,5\%, tendo em vista que o conjunto da população apresentou aumento de 592,8\% em 2014, em 
comparação com os dados de 1980. Entre 2003 e 2014, as taxas de homicídios de brancos caem 27,1\% - de 14,5 em 2003 para 10,6 em 2014 -, enquanto que a taxa de homicídios de negros aumenta 9,9\%: de 24,9 para 27,4. A violência racial, que em 2003 era de $71,7 \%$, foi um crescente no país, atingindo 158,9\% em 2014. Assim, morrem 2,6 vezes mais negros que brancos por arma de fogo (Waiselfisz, 2016).

Isso é apontado pelo rapper e produtor musical, MC Pingo do Rap sobre a exclusão "ao circular fora da favela, os moradores enfrentam preconceito e racismo. Toda vez alguém muda de calçada. Está na cor da minha pele, no cabelo, no modo de me vestir. As pessoas te veem no ônibus e seguram a bolsa mais forte ${ }^{3 "}$ relata.

Para Hasenbalg (2005), essas desigualdades são atravessadas pelo mito da democracia racial e pela perspectiva de luta de classes, ambas amparadas na minimização ou no não reconhecimento/invisibilidade da intersecção raça para as questões sociais. Dados de Pesquisas do Instituto de Pesquisa Econômica Aplicada (IPEA) apontam o reconhecimento dos negros brasileiros como um segmento com características específicas e desvantajosas em termos de inserção social no país (Carneiro, 2011).

Na Cartilha Subsídios para o debate sobre a questão étnico-racial na formação em Serviço Social ${ }^{4}$, esses indicadores sociais são discutidos:

\begin{abstract}
Pesquisa do IBGE (2011: 53) aponta que nas taxas de analfabetismo das pessoas de 15 anos ou mais de idade, tanto pretos $(14,4 \%)$ quanto pardos $(13,0 \%)$ mostram um percentual de analfabetismo quase três vezes maior do que o dos brancos (5,9\%). Assim, pobreza e não acesso a educação expressam implicações sociais que atingem diretamente a classe trabalhadora negra desse país. Os dados do censo do IBGE (2011) contabilizaram em 2010 uma população brasileira superior a 190 milhões de habitantes. As informações relativas aos números de brasileiros/as por curso mais elevado concluído na área da educação revelam a desigualdade racial enquanto uma marca das relações raciais no Brasil. No nível mais elementar do ensino fundamental e faixa etária adequada há certo equilíbrio com $51 \%$ de negros(as), 47,6\% de brancos(as) e 1,4\% de amarelos(as)/indígenas. Segundo o Censo, em 2000 apenas 1,7\% da população brasileira frequentava o ensino superior $(0,7 \%$ da população negra e $2,5 \%$ da população branca). Em 2010, embora a frequência bruta tenha aumentado (3,3\% da população), a
\end{abstract}

\footnotetext{
${ }^{3}$ Disponível: <https://radis.ensp.fiocruz.br/index.php/home/reportagem/nossas-vidas-importam>. Acesso em: 17 set. de 2020.

${ }^{4}$ Ao elaborar este documento base para o Subsídio ao Debate da Questão Étnico-Racial na Formação em Serviço Social, a gestão da Associação Brasileira de Ensino e Pesquisa em Serviço Social (2017-2018) coloca como uma das centralidades da sua agenda política o compromisso na construção de um projeto de formação profissional antirracista e reconhece o significado sócio-histórico do debate étnico-racial para o Serviço Social brasileiro.

Disponível em:

<http://www.abepss.org.br/arquivos/anexos/subsidio_debate_uestao_etnico_servico_social-

201812041419427146430.pdf>. Acesso em: 02 jul. de 2019.
} 
desigualdade persiste (2,3\% negros - 4,3\% brancos). Quanto maior o nível de escolaridade, mais visível é a desigualdade. Em relação aos cursos de mestrado e doutorado há que se destacar que $80,7 \%$ dos estudantes neste nível são brancos, $17,1 \%$ negros e 2,2\% correspondem aos grupos populacionais amarelos e indígenas (Silva, 2013: 20).

Zubaran, Wortmann e Kirchof (2016) ressaltam que é a partir dos sistemas classificatórios disponíveis nas culturas em que estamos inseridos que definimos quem somos e quem podemos ser. Para Hall (1997), não existem significados culturais essenciais, fixos e imutáveis, pois devem ser analisados à luz das suas contradições, contingências e transformações sócio-históricas. A jovem Tulipa (18 anos) ressaltou na entrevista narrativa: "Meu filho é moreno, meu esposo é negro. Quando meu filho nasceu, eu coloquei a mão na consciência; não quero que meu filho chegue à escola e chamem ele de preto, macaco" (7 de dezembro de 2018). Fica perceptível na narrativa dessa jovem-mãe o medo do racismo associado ao risco de o filho sofrer violência étnico-racial no espaço escolar. O estudo da cultura deve reconhecer que toda prática social expressa ou comunica um significado e, portanto, são práticas significantes (HallL, 1997). Nesse sentido, reavalia seus padrões de conduta pública e o quanto isso pode interpelar os modos de ser e viver do filho na sua condição estudantil.

Consta na cartilha Subsídios para o debate sobre a questão étnico-racial na formação em Serviço Social que a questão étnico-racial se constitui como um elemento estruturante das relações sociais e, assim, deve ser apreendida com profundidade e em toda a sua complexidade histórica. Há necessidade de materializar, nos currículos e nas propostas pedagógicas (disciplinas, atividades de ensino, pesquisa e extensão), na graduação e pós-graduação, uma gradativa e efetiva superação da secundarização/tematização da questão étnico-racial na formação, muitas vezes apreendida no viés culturalista e/ou como um segmento a ser abordado no conjunto da sociedade.

Dados do Censo do IBGE (2010) apontam que o número de pessoas que se autodeclararam pretas cresceu em $24 \%$. Isso pode indicar que estamos abdicando do subterfúgio da indefinição racial, ou seja, no dizer de Hélio Santos, “a dor da cor” ou da raça (Carneiro, 2011).

No roteiro, as perguntas que remetiam ao uso de palavras ofensivas, logo foram associadas pelos/as jovens a um teor racista, embora às vezes disfarçado de brincadeira. Isso é percebido na fala do jovem Dama da Noite (20 anos): "Por exemplo, tenho amigos negros que, no dia a dia, nós chamamos de "negão", mas nada ofensivo, para 
ofender, até mesmo porque eles me dizem se eles gostam ou não" (5 de dezembro de 2018). Guizzo e Felipe (2011) concebem que, ao longo da vida, as formas de ser e de se comportar vão sendo aprendidas, dependendo das pedagogias culturais, das novas configurações familiares e das relações de classe, raça/etnia, gênero, geração, entre outros. O comportamento do jovem acima vai nesta direção de ter aprendido que chamar de "negão" é possível, quando considerado uma "brincadeira".

A mesma situação, também, é entendida como ofensiva pelo seu colega Arueira (18 anos), que refere: Bastante palavra de baixo calão, mas também bastante palavra tipo normal: “'negão', 'alemão', sei lá, 'girafa', essas coisas, sabe? Também são palavras que são racistas, dependendo da pessoa que ouvir" (5 de dezembro de 2018). Diante disso, eles falam o que pensam e provavelmente sabem muito bem o que representam (ou podem representar), aquilo que enunciam, como nos relatos acima, ou seja, se valem de características físicas fora dos padrões para ofender um ao outro (Guizzo e Felipe, 2011).

Para Hall (2005) as identidades, devido a essas sujeições, são posições construídas em meio a relações de poder, em que a manifestação de uma identidade em detrimento de outra aflora em decorrência do contexto. Essas brincadeiras entre colegas são recorrentes nas narrativas dos/as jovens participantes. Destaca-se a narrativa da Flor de Girassol (18 anos) neste sentido: "Preconceito... Eu acho que tem brincadeiras entre amigos que tem gente que vê como preconceito e tem gente que vê como uma brincadeira" (5 de dezembro de 2018). Para a Rosa Azul (22 anos): “Ali todo mundo leva tudo na brincadeira, não levam mais na ofensa, mas, se fossem levar, nossa, teria bastante" (5 de dezembro de 2018). Guizzo e Felipe (2011: 7) salientam que "pertencer à determinada raça/cor, pertencer a uma classe social produz pertencimentos e diferenciações".

Portanto, toda representação que um sujeito confere ao outro é produzida e articulada por diferentes discursos, ou seja, "a representação é, pois, um processo de produção de significados sociais através dos diferentes discursos" (Silva, 1995: 199). O que é ofensivo torna-se aceitável nas inter-relações desses/as jovens quando identificado como humor, ou seja, uma brincadeirinha entre conhecidos. A participante Flor de Girassol (18 anos) relata o constrangimento de um colega devido aos apelidos:

Eu não sei se por que são amigos dele, não é? Acham que têm essa liberdade, têm essa intimidade de ficar brincando, mas dá para perceber... Acho que... 
Não sei se todo mundo tem o mesmo ponto de vista que eu, mas dá para perceber que ele fica aborrecido, sim (5 de dezembro de 2018).

Para Slavutzky (2014: 86), “um dos segredos do humor é que ele pode se aproximar do tabu. O tabu é proibido, algo que se deve evitar, ou ser tratado com cautela". Nas palavras de Possenti:

Se se quiser descobrir os problemas com os quais uma sociedade se debate, uma coleção de piadas fornecerá excelente pista: sexualidade, etnia/raça e outras diferenças, instituições (igreja, escola, casamento, política), morte, tudo isso está sempre presente nas piadas que circulam anonimamente e que são ouvidas e contadas por todo mundo em todo o mundo (Possenti, 2001:72).

A participante Rosa Azul (22 anos) reforça essa ideia: "Alguém no final faz alguma palhaçada, alguma coisa engraçada, aí vira frescura e já acabou. Alguém sempre tenta contornar. Nossa turma... Os alunos são muitos arreados. Então, estão sempre zoando" (5 de dezembro de 2018). Os/As jovens apropriam-se das representações existentes, reproduzindo-as e/ou recriando-as (Gamalho e Heidrich, 2014). A participante Flor de Girassol (18 anos) descreve a reação do colega zoado e a reação de boa parte da turma:

Todo mundo ri, sabe? Eu prefiro ficar mais na minha e observando, sabe? Então, eu acho que até... Então, não digo que eu sou a única, mas sou a minoria que consegue observar que ele não está gostando porque, enquanto está a turma toda rindo, eu estou observando o rosto dele, a expressão dele, que ele não está gostando (5 de dezembro de 2018).

Por isso, a importância dos territórios escolares no posicionamento diante de questões relacionadas às diferenças como ressaltado por Willinsky (1998). Essa situação relatada pela Flor de Girassol reforça os critérios de pertencimento ou de exclusão de determinado grupo social. Meyer (2002) destaca que pertencer a essa ou àquela raça/cor pode acarretar (des)vantagens, aproximar ou distanciar, unir ou separar, igualar ou diferenciar grupos ou populações. Isso fica evidenciado na fala de Arueira (18 anos) quando ele diz que:

Tinha uma colega da minha turma que mandou mensagens no Whats, no grupo da turma mesmo, falando que ela não gostava de negão. Meu colega é negão, e ela estava mandando mensagem no Whats da turma. Aí, ela falou que não gostava e até brigou com a nossa colega grávida, e essa colega grávida foi para cima dela e bateu nela. Um colega nosso, tri gente boa (5 de dezembro de 2018). 
Esta modalidade de violência na escola é "chamada cyberbullying que representa o uso da tecnologia da informação para a prática de atos hostis, deliberados e repetidos, por um indivíduo ou grupo", em direção ao outro (Andrade, 2015:21). Para a autora, essas intimidações são cada vez mais recorrentes por conta do Orkut, Facebook, MySpace, Twitter, WhatsApp e assemelhados (Andrade, 2015).

O que acontece no mundo virtual pode acompanhar o/a jovem escolar na sala de aula, e a vítima de cyberbullying pode tornar-se vítima também do bullying, cometido por colegas que acompanharam a humilhação on-line (Freitas e Casagrande, 2016). "Os cyberbullies, indivíduos que praticam o cyberbullying, provocam, xingam e ameaçam através de mensagens de celular, por e-mails ou comentários em mídias sociais (...) podem criar sites e perfis específicos em mídias sociais para difamar e agredir a vítima" (Freitas e Casagrande, 2016:113).

Feixa (2006), ao problematizar as juventudes contemporâneas, aponta que o entendimento do que é ser jovem não se limita a um grupo etário com mais acesso à Internet, nem a um grupo que vive rodeado de chats, e-mails e webs; o essencial é o impacto cultural destas novas tecnologias sobre suas visões de vida e de mundo.

Durante as observações e entrevistas realizadas, outro aspecto que chamou a atenção, foram as palavras proferidas que representam um excesso de intimidade entre esses/as jovens e que são tidas como ofensivas de acordo com o tom de voz empregado e o que está em disputa, por exemplo: raça/cor, corpo, aparência, vestuário, comportamentos entendidos como do sexo masculino/feminino, entre outros. Sobre o episódio de cyberbullying, Arueira (18 anos) reafirma essa ideia: "Foi bem racista mesmo. Ela falava que não gostava de negão, não gostava de preto e etc" (5 de dezembro de 2018).

Guizzo e Felipe (2011) salientam que as crianças (e também jovens) incorporam rapidamente noções, demandas e preconceitos vigentes na sociedade e fazem uso desses conhecimentos ofendendo colegas seja para se defenderem ou revidarem. Como expressado pela participante Tulipa (18 anos):

Hoje em dia, tem muito apelido, tem gente que gosta e tem gente que não gosta... "Negão", "moreno"... [...] daí, comecei a pensar em tudo que eu já fiz, tudo que meu marido sofreu na escola... Ele teve um episódio de ter brigado, de discutir. O colega perguntou "cadê tu, negão?" De dizerem no escuro "cadê", daí eu pensei... Meu filho, eu não quero que sofra isso, bullying" (7 de dezembro de 2018). 
De acordo com Olweus (2006), bullying ou "vitimização" caracteriza-se pela situação em que uma pessoa é atacada ou "vitimizada" e exposta, repetidamente, a ações negativas partidas de uma ou mais pessoas. Para Olweus:

[...] a expressão "ação negativa" deve ser mais especificada. É ação negativa quando alguém intencionalmente inflige ou tenta infligir, ferir ou inquietar outro - basicamente o que é entendido como comportamento agressivo. Ações negativas podem ser realizadas por palavras (verbalmente), por exemplo, ameaças, zombaria, implicância e chamando nomes. (OLWEUS, 2006: 9).

Nessa perspectiva, Amaro (2012) reconhece que a escola que deveria proteger e defender os direitos humanos e sociais, contudo abriga práticas, calcadas em atitudes racistas, sexistas e machistas, contrariando a função social que o Estado the atribui. A intolerância interfere no contexto escolar para que seja promovida uma educação cidadã, a diminuição das desigualdades e a efetiva consolidação dos direitos humanos como direito de todos (alunos/as, professores/as, corpo diretivo e famílias).

Deste modo, interessou-me não só a forma como as/os jovens entrevistadas/os apreendem o que as/os circunda, mas também como (re)produzem essas experiências entre si no território escolar. Valho-me das contribuições de Zubaran e Gonçalves e Silva (2012: 132) quando argumentam que:

[...] retomar os conceitos de raça e etnia significa também questionar as representações étnico-raciais dominantes, problematizá-las e desnaturalizálas. Somente assim abriremos espaço para a construção de representações culturais alternativas e plurais dos diferentes sujeitos que interagem na escola e nos demais espaços educativos.

A fala da jovem escolar Rosa Azul (22 anos) enfatiza essa ideia: A gente fala: "vamos embora com fulano porque fulano é preto e ninguém assalta preto" (5 de dezembro de 2018). A criminalização das ações juvenis brasileiras é uma problemática moralizada que ganha corpo e incorpora marcas simbólicas amplamente disseminadas pela mídia, mas diferenciada, pois patologiza jovens ricos/as e culpabiliza jovens pobres e, em especial, os/as jovens negros/as. Trata-se de desigualdades realçadas pela discriminação e pelo racismo. Para Zamboni:

Os marcadores sociais da diferença nunca aparecem de forma isolada, eles estão sempre articulados na experiência dos indivíduos, no discurso e na política. Finalmente, os sistemas de classificação estão intimamente ligados 
às relações de poder. Estão, portanto, sempre em disputa - das relações pessoais à política (Zamboni, 2016: 15).

Nesta perspectiva, Zamboni reforça que esses demarcadores estão ligados a relações de poder e sistemas de dominação mais amplos, sendo responsáveis pela (re) produção de desigualdades. Segundo Carneiro (2011), vivemos em um tipo de sociedade em que o caráter estrutural do racismo impede a realização dos fundamentos da democracia, posto que semelhante sociedade consagra hegemonias e subalternizações racialmente recortadas. Carneiro (2011) observa que o aparelho educacional tem focalizado, especialmente, os racionalmente inferiorizados, ou seja, o epistemicídio, na medida em que ocorre o rebaixamento da autoestima que o racismo e a discriminação provocam no cotidiano escolar, pela imposição do embranquecimento cultural e pela produção do fracasso escolar e da evasão. Para Almeida:

Podemos dizer que o racismo é uma forma sistemática de discriminação que tem a raça como fundamento, e que se manifesta por meio de práticas conscientes ou inconscientes que culminam em desvantagens ou privilégios para indivíduos, a depender do grupo racial ao qual pertençam. (Almeida, 2018: 25)

Diante disso, pode-se mencionar a Lei 10.639 de 2003, que estabelece as diretrizes e bases da educação nacional, para instituir a obrigatoriedade do ensino da cultura e história afro-brasileiras e africanas, alterando a Lei n ${ }^{\circ}$ 9.394, de 1996 (Kirchof et al., 2015). Dos/as oito jovens entrevistados/as, apenas o participante Arueira (18 anos) referiu a abordagem desse conteúdo: "Foi um teatro que a gente fez e teve um negócio sobre os negros, em que uma marquesa comprava, com o seu marido, alguns escravos, e alguns serviam e outros não. Foi bem legal" (5 de dezembro de 2018).

Isso reforça a ideia com relação a determinadas populações identificadas pela referência às suas características fenotípicas. O conceito de racialização é sistêmico, visto que opera com objetivos definidos; é polissêmico, pois se constrói a partir de múltiplos sentidos discursivos; e é multidirecional, ao dirigir-se a todos os sujeitos, independentemente de gênero, nacionalidade, classe e pertencimento étnico (Kaercher, 2010).

Conforme Zubaran e Gonçalves e Silva (2012), na sociedade brasileira, parte-se dos posicionamentos que reconhecem o esgotamento das macroabordagens na análise educacional e que enfatizam a necessidade de inserção e discussão de novas temáticas, 
como, por exemplo, a diversidade étnico-racial, para repensar a escola e as práticas pedagógicas na sociedade brasileira contemporânea. As autoras problematizam:

\begin{abstract}
Como se constroem os sentidos de pertencimento e de exclusão étnico-raciais na sociedade brasileira contemporânea? Quem é negro no Brasil? Um dos aspectos fundamentais da discussão sobre o pertencimento étnico-racial no Brasil parece estar vinculado ao processo de desnaturalização do conceito de raça na sociedade brasileira, especialmente nas suas instâncias formadoras, como a escola e os currículos culturais da mídia (Zubaran; Gonçalves; Silva, 2012: 131)
\end{abstract}

Abramovay e Rua (2002) afirmam que as violências na escola têm identidade própria, ainda que se expressem mediante formas comuns, como incivilidades, preconceitos e desconsiderações aos outros e às diversidades. Este tema de análise transcende o território escolar, uma vez que um país que aspira a transformações estruturais tem de enfrentar, no seu planejamento estratégico, eufemismos ou silêncios que historicamente mascaram as desigualdades raciais. A maioria dos excluídos tem cor e sexo, então, as políticas públicas e sociais têm que levar em consideração essas dimensões (Carneiro, 2011).

Evidências empíricas apontam, neste estudo, que integrantes dos grupos ditos vulneráveis também ocupam posições de agressores/as, discriminadores/as ou ofensores/as. Eles também se utilizam de outras violentas hierarquias estabelecidas por meio de intersecções, como raça, classe social, gênero e/ou sexualidade.

\title{
Meu cabelo te bateu, te xingou?
}

As violências disfarçadas de brincadeira acontecem de forma recorrente entre os/as jovens que frequentam a escola pesquisada. Este tipo de conduta tem sido frequente entre os/as escolares. $\mathrm{Na}$ análise das narrativas, ressoaram questões de racismo, algumas concernentes ao cabelo como marca da diferença. Isso fíca evidenciado na fala da participante Rosa Azul (22 anos): "Nós ali, a gente sempre brinca, mas, em outras situações, se fossem outras pessoas, quem vê de fora, acha que está sendo preconceituoso com o colega e tal" (5 de dezembro de 2018). Há que se ressaltar que o bullying extrapola o espaço escolar, como relatado acima e pode desencadear uma série de problemas sociais, inclusive suicídios, massacres, evasão escolar, sentimentos de inferiorização e constrangimento a partir de alguma característica atribuída a algum sujeito em particular, entre outros. 
Nota-se o impacto do racismo e da discriminação nas identidades negras. Nogueira, em sua tese, Significações do corpo negro, afirma que:

[...] o negro depara com o esfacelamento de sua identidade negra, ele se vê obrigado a internalizar um ideal de ego branco. No entanto, o caráter inconciliável desse ideal de ego com sua condição biológica de ser negro exigirá um enorme esforço a fim de conciliar um ego e um ideal, e o conjunto desses sacrifícios pode até mesmo levar a um desequilíbrio psíquico (Nogueira, 1998: 88).

Para Guizzo e Beck (2011), embora meninas/mulheres e meninos/homens se preocupem com a aparência, as primeiras cobranças com relação aos padrões de beleza vigentes ainda são bem maiores às meninas/mulheres. As autoras ressaltam que tais cobranças são oriundas de infinitas instâncias culturais, visuais e sociais, que têm o poder de produzir, demarcar, regular e diferenciar os corpos (Guizzo e Beck 2011). A narrativa de Rosa Azul (22 anos) reafirma essa ideia:

Mas às vezes a gente fala "fulano tem o cabelo ruim que nem o meu namorado", "tem o cabelo ruim que nem o do fulano". Daí, ele fala: "Sim, meu cabelo é ruim, por quê? Meu cabelo te bateu, te xingou", mas outras pessoas levariam como ofensa (5 de dezembro de 2018).

Embora, quaisquer atributos físicos possam ser colocados em evidência no contexto escolar, tais como: ser gordo/a, ser pessoa com deficiência, ter dificuldade para aprender, entre outros, foram as características étnico-raciais que tiveram mais ressonância nas entrevistas. Carrano (2014) pondera que é por meio dos gestos, dos símbolos, das formas de utilizar o corpo, de viver e de agir, que os/as jovens produzem a experiência comunitária de vivência da juventude. Santos (2015), em sua dissertação, intitulada Cabelo como traço da diferença em livros para crianças, ressalta que há duas formas de contestar estereótipos e reposicionar o cabelo (crespo) no lugar da beleza, seja pela vinculação explícita com a ancestralidade africana, seja pela denúncia e superação de situações ficcionalizadas de racismo.

Contudo, no Brasil, as heranças genéticas, que incluem a cor da pele, o tipo de cabelo, a espessura dos lábios e do nariz, são significadas como diferenças que importam para demarcar diferenças raciais, bem como para classificar alguém como bonito/a ou feio/a (Andrade, 2008). Esse entendimento foi explicitado pelo participante Girassol (18 anos): 
[...] estava falando de cabelo com a minha amiga, ela é negra, e ela alisa o cabelo. Eu perguntei desde quando ela alisava o cabelo, e ela disse que desde pequena. Perguntei por quê. Ela disse que sofria bullying pelo cabelo ser cacheado, volumoso, mas que hoje ela aceita isso, ela não leva como trauma, mas nunca mais quer deixar o cabelo crespo, que talvez não afete psicologicamente a pessoa, mas afete inconscientemente [para que] ela siga padrões estéticos (7 de dezembro de 2018).

O relato desse jovem escolar sobre os cabelos de uma amiga diz respeito à relação de muitas meninas, jovens e mulheres que por falta de representatividade e por sofrerem violências étnico-raciais, acabam por recorrer a vários procedimentos de embelezamento (chapinha e babyliss) ou por meio de produtos químicos para alisarem seus cabelos afros. Para Sibilia (2008), a definição de "quem somos" está estreitamente ligada ao reconhecimento e à valorização do olhar do outro. No Brasil, as mulheres negras feministas e as influenciadoras digitais (youtuber) têm discutido, amplamente, esses padrões sociais e estéticos impostos às meninas, jovens e mulheres e que muitas têm optado pela transição capilar, ou seja, um processo em que a pessoa abandona qualquer tipo de química para dar lugar ao cabelo natural.

Pereira refere que "vivemos um período histórico e cultural no qual somos expostos diariamente a muitos estímulos visuais, desenvolve-se uma tendência a transformar tudo em imagem" (2017, on-line ${ }^{5}$ ). Portanto, as nossas referências são múltiplas, dinâmicas e muito glamorosas nas quais os corpos e as vidas fantásticas exibidas pela mídia, pelo marketing das celebridades, e mais recentemente, pelas narrativas de youtubers e blogueiras acabam por produzir um repertório de imagensmodelo (Pereira, 2017, on-line).

É possível correlacionar essa desconstrução dos padrões estéticos com base em Berth (2019), que concebe o empoderamento como um conceito que estabelece um conjunto de práticas que visam à emancipação sociopolítica de indivíduos inseridos em grupos expostos a opressão, tais como: mulheres, negros, indígenas e LGBTIs. Silva (2013) considera que a diferença é vista não como produto da identidade, mas como uma operação de diferenciação. Tal postulado origina-se na linguística, visto que a identidade e a diferença são construídas por meio de atos de linguagem, a partir de práticas simbólicas, sociais e culturais. Para Zamboni:

\footnotetext{
5 In: Anais do $7^{\circ}$ Seminário Brasileiro de Estudos Culturais e Educação / $4^{\circ}$ Seminário Internacional de Estudos Culturais e Educação. Canoas: PPGEDU, 2017.
} 
Marcadores sociais da diferença são sistemas de classificação que organizam a experiência ao identificar certos indivíduos com determinadas categorias sociais. Em termos de raça, por exemplo, os indivíduos podem ser classificados como negros ou brancos, morenos ou mulatos, asiáticos ou indígenas. Cada uma dessas categorias de classificação está associada a uma determinada posição social, possui uma história e atribui certas características em comum aos indivíduos nela agrupados (Zamboni, 2016: 13).

Carneiro (2011) alerta que somos interpelados a usar a miscigenação ou a mestiçagem como uma carta de alforria do estigma da negritude. Cabelos mais lisos são suficientes para fazer com que alguém que descende de negros se sinta pardo ou branco, ou possa ser promovido socialmente a essas categorias. Em um excerto do Post $^{6}$ de Djamila Ribeiro no Instagram sobre a zagueira da França ter sofrido racismo por causa do seu cabelo afro questiona:

Quantas mulheres negras se violentam para atender a imposição de padrão estético? Quantas feridas causadas no couro cabeludo, na autoestima? Quantas violências no cotidiano escolar? Desde "não vou dançar com a neguinha do cabelo duro"” a "por que você não alisa seu cabelo?" Só a gente sabe. Só as mulheres dos cabelos crespos, que não fazem cachos, sabem. Só as dos 'cabelos sem definição', sabem.

Isso expõe a violência étnica racial enfrentada por milhares de meninas, jovens e mulheres com relação ao cabelo afro em seus cotidianos de vida familiar, escolar e laboral. Ressalta-se que se estas meninas, jovens e mulheres decidirem que seus cabelos sejam lisos, que tenham liberdade e não sofram opressão por conta disso. Conforme Guizzo e Beck (2011: 25), a identidade étnica e racial indica que:

Embora o Brasil seja um país com uma imensa miscigenação, o padrão de beleza mais valorizado é o branco, ou seja: cabelos lisos, compridos e claros. Não é a toa que, hoje em dia, infinitos tratamentos são oferecidos no mercado estético-capilar, como: escova progressiva, escova inteligente, escova de chocolate, escova marroquina, escova indiana, chapinha, escova tradicional, apliques para alongar os cabelos, perucas feitas de cabelos naturais, etc.

Para Bonin, Ripoll e Guizzo (2016), o entendimento de que somos diferentes fortalece as tendências a um diferencialismo útil ao mercado. Assim, podemos pensar que o reconhecimento das diferenças se acomoda e se conforma a uma celebração e valorização de uma "natural" diversidade, sem necessariamente conduzir a uma problematização das relações de poder a partir das quais se estabelecem posições de

\footnotetext{
${ }^{6}$ Disponível: <https://www.instagram.com/djamilaribeiro1/?utm_source=ig_embed>. Acesso em: 21 Set. de 2020.
} 
sujeitos. A jovem escolar Rosa Azul (22 anos) observa: "Na aula de filosofia, a professora, não sei se confunde com religião ou filosofia, mas ela traz bastante esses assuntos, que nem a questão de preto, que eu falei do cabelo, ela trouxe uma questão sobre isso" (5 de dezembro de 2018).

Santos (2016), em sua dissertação, mostra que as obras de literatura infantil por ela analisadas reforçam a questão do cabelo como um traço distintivo, como marca da diferença, sendo que as narrativas confluem para a exaltação do cabelo "ao natural”, e os desfechos são encaminhados no sentido de promover sua aceitação e valorização. Neste sentido, a diferença é essencial ao significado, e o significado é crucial à cultura. (Hall, 2005). O corpo é significado culturalmente e pode ser considerado um local de inscrição de significados da cultura; o valor atribuído ao cabelo vai por essa direção, ou seja, o cabelo é alvo de grandes preocupações e investimentos de mulheres e meninas (Guizzo e Beck, 2011).

De acordo com Abramovay (2002), tanto os/as jovens quanto outros membros do espaço escolar relatam que a violência deixou de ser um componente de excepcionalidade e se disseminou a tal ponto que se naturalizou, se banalizou, passando a ser elemento comum no cotidiano. Como já foi contextualizada, a construção da identidade ocorre por meio de sistemas classificatórios, e o posicionamento entre identidade e diferença poderia organizar-se, sob essa perspectiva, em torno de oposições binárias: masculino/feminino, branco/negro, heterossexual/homossexual. Então, "questionar a identidade e a diferença como relações de poder significa problematizar os binarismos em torno dos quais elas se organizam" (Silva, 2013: 88).

Pinto (1989: 45) diz que o discurso do senso comum pode ser compreendido como aquele que tem "a capacidade de dar sentido à vida cotidiana e uma enorme potencialidade de ser articulado a diferentes visões de mundo", de modo amplo, de fácil entendimento para a população. Não raro, acaba por orientar os processos educacionais, sociais e culturais por meio dos quais crianças, jovens e adultos são educados/as (Guizzo e Beck, 2011).

Caberia perguntar em que medida normas de comportamento e práticas corporais vigentes no espaço escolar estão implicadas na produção de diferenças e desigualdades de gênero potencialmente violentas (Meyer, 2009). Diante disso, as violências disfarçadas de brincadeiras pressupõem a aceitação dessa conduta e prática por parte daqueles/as que não estão diretamente implicados na situação (alunos/as, professores/as, corpo diretivo e famílias). 
Nos espaços escolares, alunos/as podem ser considerados/as como testemunhas, porém acabam por legitimar os episódios de bullying, pois a conduta de passividade ou impotência pode representar uma aceitação ou uma postura de não envolvimento. As narrativas desses/as participantes que presenciaram episódios de bullying apontam para uma postura omissa com relação aos professores/as, corpo diretivo e famílias.

Em entrevista concedida à CartaCapital, Moreira $^{7}$ afirma que as piadas que ofendem negros/as são entendidas como racismo recreativo e que "o humor racista é um tipo de discurso do ódio, é um tipo de mensagem que comunica desprezo, que comunica condescendência por minorias raciais". Isso representa uma das tentativas de camuflar o racismo na nossa sociedade, contudo expressa a depreciação, inferiorização do outro, apenas por ser quem é e por ter cabelo afro.

Contudo, ressalta-se a importância da escola nesse debate, reflexão e compreensão das identidades e diferenças, pois essas estratégias de enfrentamento às violências, em especiais, as étnico-raciais fazem-se, extremamente, necessárias. Se houver uma omissão por parte dos/as profissionais da escola, isso poderá permitir que as violências se perpetuem. Neste sentido, foi aprovada a Lei 13.185, de 6 de novembro de 2015, que instituiu o programa de combate à intimidação sistemática ou bullying $e$ obriga escolas a adotarem medidas antibullying.

Apesar da gravidade do bullying, não se entende que esse é um problema a ser também regulamentado no âmbito das políticas escolares nacionais, mas que é atribuído à unidade escolar. A regionalização da discussão e a sua regulamentação são importantes por considerar as peculiaridades do problema em cada região. Contudo, atribuir à unidade escolar a responsabilidade e a resolução do problema é trazer mais uma responsabilidade para a escola, sem que haja um respaldo institucional para se tratar da questão.

Na prática, isso pressupõe um trabalho pedagógico efetivo e sistemático (não episódico e pontual como muitas vezes ainda se observa nas escolas). Haja vista que ainda há uma tentativa de se individuar esse problema social, levando à diminuição da questão, pois de acordo com esse entendimento a adoção de práticas inibidoras das violências seria suficiente para resolver a questão. Com relação à responsabilidade da direção do Colégio na manutenção das violências, temos a narrativa de Rosa Azul (22 anos):

\footnotetext{
${ }^{7}$ Disponível: <https://www.cartacapital.com.br/justica/adilson-moreira-o-humor-racista-e-um-tipo-dediscurso-de-odio/>. Acesso em: 22 set. de 2020.
} 


\begin{abstract}
Acho que eles têm que tentar conhecer mais os alunos, tentar dar mais palestras sobre isso, tentar ver se alguém tem algum problema, chamar para conversar. Vamos ver se dá para ajudar de alguma forma, procurar ajuda para essa pessoa, porque, se ela está fazendo, tem muita raiva dentro de si, é porque está com algum problema. A escola não faz isso. Única coisa que faz é convidar a se retirar da escola (5 de dezembro de 2018).
\end{abstract}

Salienta-se que mesmo em se tratando de jovens escolares, é perceptível que esses/as demandam a solução dos problemas relacionados às violências na/da escola aos professores e ao corpo diretivo. Neste sentido, nem são crianças que demandam tal intervenção profissional e nem adultos para lidarem com seus desconfortos e desafetos com autonomia, contudo por vezes narram o desejo de serem protagonistas nos/dos processos educativos. Portanto, os modos de ser e viver a juventude muda de acordo com o que está em jogo, além da ausência de espaços de participação que acabam por esconder as conflitividades presentes.

\title{
Considerações Finais
}

Ao longo deste artigo buscamos, a partir do material empírico organizado em decorrência da transcrição das entrevistas, problematizar como as violências que se articulam às questões de raça, gênero e corpo são representadas, produzidas e narradas por jovens que frequentam uma escola da rede estadual, localizada no território do Guajuviras em Canoas/RS. Como procuramos evidenciar ainda não há um trabalho pedagógico efetivo no sentido de promover um espaço mais democrático e equitativo para todos e todas.

Em virtude disso, o ambiente escolar estudado poderia promover estratégias educativas e programáticas que possibilitem discussões, reflexões e propostas que contemplem as identidades de gênero e étnico-raciais, bem como as culturas juvenis, a cultura do corpo, cultura da paz, entre outros temas. Tudo isso deveria estar alinhado ao Projeto Político Pedagógico da escola estudada, uma vez que esse documento enfatiza o desenvolvimento dos/as alunos/as por meio de competências éticas, afetivas, a interlocução de relações intrapessoais e interpessoais nos diferentes contextos sociais. Reconhece-se que as narrativas desses/as jovens vinculados/as a uma escola do território do Guajuviras fornecem várias dimensões (símbolos, mitos, recursos, práticas) que constroem uma cultura comum, embora sejam muito diferentes entre si.

Enfim, é importante ressaltar que a naturalização das desigualdades relacionadas à violência racial e de gênero tem provocado inúmeras formas de dominação, opressão e 
violências àqueles/as que vivenciam identidades consideradas como não hegemônicas. Durante a realização das entrevistas notou-se uma dupla dimensão: privada e pública que se atravessam entre si (família, escola, comunidade) para a desconstrução das violências representadas pela cultura machista, racista, patriarcal quer perpetrada entre os/as jovens participantes ou professores/as e corpo diretivo da escola. Portanto, o respeito às diversidades e identidades de gênero e raça-cor deveriam envolver, por parte da escola e das redes intersetoriais e interprofissionais, estratégias pedagógicas e ações programáticas para discussão sobre as formas de preconceito e discriminação reproduzidas na sociedade.

\section{Referências}

ABRAMOVAY, M. e RUA, M. G. Violências nas escolas. Brasília: UNESCO, Coordenação DST/AIDS do Ministério da Saúde, Secretaria de Estado dos Direitos Humanos do Ministério da Justiça, CNPq, Instituto Ayrton Senna, UNAIDS, Banco Mundial, USAID, Fundação Ford, CONSED, UNDIME, 2002.

ALMEIDA, Silvio Luiz de. O que é racismo estrutural? Belo Horizonte (MG): Letramento, 2018.

ANDRADE, Cláudia Braga de. Violências e juventudes: processos de subjetivação no contexto escolar. Bol. psicol, São Paulo, v. 65, n. 142: 15-28, jan. 2015 .

BERTH, Joice. O que é empoderamento. BH: Letramento/Justificando, 2018.

BONIN, Iara T., RIPOLL, Daniela e GUIZZO, Bianca S. Para pensar a educação e as diferenças sob um enfoque cultural. Em Aberto, v.29, n. 95:25-37, 2016.

BRASIL. Constituição República Federativa do Brasil: promulgada em 5 de outubro de 1988. 17. ed. São Paulo: Saraiva, 1997.

BRASIL. Estatuto da Criança e do Adolescente. Lei n. 8069/90. In: Conselho Regional de Serviço Social - CRESS $11^{a}$ Região. Coletânea de Legislações: direitos de cidadania. Curitiba: CRESS/Gráfica Capital, 2003.

BRASIL. Ministério da Saúde. Secretaria de Políticas de Saúde. Violência intrafamiliar: orientações para prática em serviço / Secretaria de Políticas de Saúde. - Brasília: Ministério da Saúde,96 p.: il. - (Série Cadernos de Atenção Básica; n. 8) - (Série A. Normas e Manuais Técnicos; n. 131), 2001.

BRASIL. LEI 13.185 de 6 de novembro de 2015. Programa de Combate à Intimidação Sistemática (Bullying). Diário Oficial da União, Brasília, 6 de novembro de 2015.

CARNEIRO, Sueli. Racismo, Sexismo e desigualdade no Brasil. São Paulo: Selo Negro, 2011. (Consciência em debate/coordenadora Vera Lúcia Benedito). 
CARRANO, Paulo César Rodrigues. Identidades juvenis e escola. In: Construção coletiva: contribuições à educação de jovens e adultos. - Brasília: UNESCO, MEC, RAAAB, 2005. 362p. - (Coleção educação para todos; 3). ISBN: 85-7652-049-4 1. Educação de Adultos 2. Educação Universal 3. Democratização da Educação I. UNESCO II. Brasil. Ministério da Educação III. RAAAB

CARRANO, Paulo César Rodrigues. Identidades juvenis e escola. Alfabetização e Cidadania. São Paulo: Rede de Apoio à Ação Alfabetizadora no Brasil (RAAAB), nov. 2000. n. 10.

CARRARA, Sérgio. Políticas edireitos sexuais no Brasil contemporâneo. Revista Bagoas, n. 05. Natal: UFRN, 2010: 131- 147

COSTA, Marisa Vorraber (org.). Sobre as contribuições das análises culturais para a formação dos professores do início do século XXI. Educ. rev., Curitiba, no 37: 129-152, May 2010.

DAL’IGNA, Maria Cláudia; KLEIN, Carin; MEYER, Dagmar Estermann.

Generificação das práticas curriculares: uma abordagem feminista pós-estruturalista. Currículo sem Fronteiras, v. 16, n. 3: 468-87, set./dez. 2016.

DAYRELL, Juarez (organizador). O jovem como sujeito social. Revista Brasileira de Educação, São Paulo, 2003.

. (2002). O rap e o funk na socialização da juventude. Educação E Pesquisa, 28 (11), 117-136.

DEBERT, Guita Grin. Pressupostos da reflexão antropológica sobre a velhice. In:

DEBERT, Guita Grin. A antropologia e a velhice - Textos Didáticos, Campinas, v. 1, n. 13, 1998: 07-28.

FEIXA, Carles. Generación $X X$. Teorías sobre la juventud enla era contemporánea. Revista Latinoamericana de Ciencias Sociales, Niñez y Juventud[on-line]. 2006, vol.4, n.2.

FELIPE, Jane e GUIZZO, Bianca Salazar. Erotização dos corpos infantis na sociedade de consumo. Pro-posições, Campinas, v. 14, n.3(42), set./dez. 2003:119-132.

Gênero, sexualidade e a produção de pesquisas no campo da educação: possibilidades, limites e a formulação de políticas públicas. ProPosições, v. 18, n. 2 (53) - maio/ago. 2007a.

FREITAS, Lucas Bueno de., CASAGRANDE, Lindamir Salete. "Era só uma brincadeira!": Reflexões sobre bullying escolar e suas consequências. In: Entrelaçando gênero e diversidade: violências em debate. / Nanci Stancki da Luz, Lindamir Salete Casagrande (org.). - Curitiba: Ed. UTFPR, 300 p.: il. ISBN: 978-85-7014-179-8, 2016.

GAMALHO, N.P; HEIDRICH, A. L. "Percursos entre centralidades, periferias, ocupações e vilas: as representações do espaço de jovens do Guajuviras - Canoas/RS". Mouseion 19 (2014): 127-147. 2014. 
GUIZZO, B. S., BECK, D. Q. Corpo, gênero, erotização e embelezamento na infância. Textura. Rio Grande do Sul, n.24; p.1636; jul./dez 2011.

GUIZZO, B. S., FELIPE, Jane. Atravessamento de raça/cor e classe social: discriminações no âmbito da Educação Infantil. Políticas Educativas, Porto Alegre, v. 4, n.2: 70-83, 2011.

HALL, S. The work of representation. In: Representation. Cultural Representations and Signifying Practices. London/Thousand Oaks/New Delhi Sage/Open University, 1997.

. A Identidade Cultural da pós-modernidade. $10^{\mathrm{a}}$ edição. Rio de Janeiro:

DP\&A, 2005.

A centralidade da cultura: notas sobre as revoluções culturais do nosso tempo. Educação \& Realidade, Porto Alegre, v. 22, nº 2: 15-46, jul./dez. 1997.

HASENBALG, C. A. A discriminação e desigualdades raciais no Brasil. Tradução de Patrick Beurglion. 2. ed. Rio de Janeiro: Graal, 2005 [1979].

KAERCHER, Gládis Elise Pereira da Silva. Pedagogias da racialização ou dos modos como se aprende a ter raça e/ou cor. In: BUJES, Maria Isabel Edelweiss; BONIN, Iara Tatiana (org.). Pedagogias sem fronteiras. Canoas, RS: ULBRA, 2010. p. 85-91.

LOURO, Guacira Lopes. Gênero, sexualidade e educação - uma perspectiva pósestruturalista. 12a ed. Petropólis, RJ: Vozes, 2011.

Currículo, gênero e sexualidade: o "normal", o "diferente" e o "excêntrico". In: LOURO, Guacira; NECKEL, Jane Felipe; GOELLNER, Silvana Vilodre (org.). Corpo, gênero e sexualidade: um debate contemporâneo na educação. Petrópolis: Vozes, 2003. P. 41-52.

MEYER, Dagmar Estermann. Das (im)possibilidades de se ver como anjo. In: GOMES, N. L.; GONÇALVES E SILVA: B. (org.). Experiências étnico-raciais na formação de professores. Belo Horizonte: Autêntica, 2002, 51-70.

Teorias e políticas de gênero: fragmentos históricos e desafios atuais. Rev. Bras. Enferm, Brasília, v. 57, n. 1: 13-18, Feb. 2004.

MOREIRA, Adilson. O que é racismo recreativo. BH: Letramento/Justificando, 2019.

NOGUEIRA, Izildinha Baptista. Significações do corpo negro. Tese (Doutorado em Psicologia Escolar e Desenvolvimento Humano) - Universidade de São Paulo (SP), 1998:88.

OLWEUS, Dan. Bullyingatschool: what wek now and what we can do. Malden: Blackwell, 2006.

POSSENTI, Sírio. O humor e a língua. Ciência Hoje, v. 30, n. 176. Out. 2001. Disponível em: $<$ http://aescritanasentrelinhas.com.br/wp-content/uploads/2009/02/ohumor-e-a-lingua-texto.pdf $>$. Acesso em: 05 de agosto de 2020. 
REGUILLO, Rossana. Emergência de culturas juveniles: estratégias del desencanto. Buenos Aires: Norma, 2000.

SCOTT, Joan. Gênero: uma categoria útil de análise histórica. Educação e Realidade, Porto Alegre: Faced/UFRGS, v. 20, n. 2: 71-99, 1995.

SIBILIA, Paula. O show do eu: a intimidade como espetáculo. Rio de Janeiro: Nova Fronteira, 2008.

SILVA, T. T. da. Currículo e Identidade Social: territórios contestados. In: Alienígenas na Sala de aula: uma introdução aos estudos culturais em educação. Petrópolis: Vozes, 1995.

Identidade e diferença: a perspectiva dos estudos culturais. Tomaz Tadeu da Silva (org.). Stuart Hall, Kathryn Woodward. 13. ed. - Petrópolis, RJ: Vozes, 2013.

SLAVUTSKY, Abraão. Humor é coisa séria. Porto Alegre: Arquipélago Editorial, 2014.

SPOSITO, Marilia Pontes (coord.). O estado da arte sobre juventude na pós-graduação brasileira: educação, ciências sociais e serviço social (1999-2006). V. 1. Belo Horizonte: Argvmentvm, 2009.

A pesquisa sobre jovens na Pós-Graduação: um balanço da produção discente em Educação, Serviço Social e Ciências Sociais (1999-2006). In: (Coord.). O Estado da O Estado da Arte sobre juventude na pós-graduação brasileira: Graduação brasileira Educação, Ciências Sociais e Serviço Social (1999-2006). Belo Horizonte: Argumentum, 2009.

VARGAS, Juliana Ribeiro de. Meninas (mal)comportadas: posturas e posicionamentos em uma escolar pública de periferia. Porto Alegre: UFRGS, 2008. 135f. Dissertação (Mestrado em Educação). Programa de Pós-Graduação em Educação. Faculdade de Educação. Universidade Federal do Rio Grande do Sul, 2008.

WAISELFISZ, Júlio Jacobo. Mapa da violência 2016 homicídios por armas de fogo no Brasil. Rio de Janeiro, FLACSO/CEBELA, 2015.

WILLINSKY, John. Learning to divide the world: education at empire's end. Minneapolis-London: University of Minnesota Press, 1998.

ZAMBONI, Marcio. Marcadores Sociais. Sociologia Especial: 13-18, 2016.

ZUBARAN, Maria Angélica; WORTMANN, Maria Lúcia; KIRCHOF, Edgar Roberto. Stuart Hall e as questões étnico-raciais no Brasil: Cultura, representações e identidades. Projeto História: Revista do Programa de Estudos Pós-Graduados de História, [s.l.], v. 56, out. 2016. ISSN 2176-2767.

ZUBARAN, Maria Angélica; SILVA, GONÇALVES, Petronilha Beatriz. Interlocuções sobre estudos afro-brasileiros: Pertencimento étnicoracial, memórias negras e patrimônio cultural afro-brasileiro. Currículo sem Fronteiras, v. 12, n. 1, pp. 130-140, jan./abr. 2012. 
Cidades em metamorfose: memórias, percursos urbanos e imagens

Data de submissão: 15 de julho de 2020

Data de publicação: 20 de dezembro de 2021 